\title{
Photoluminescence in the solid solution $\operatorname{In}_{0.5} \mathrm{Tl}_{0.5} \mathrm{I}$
}

\author{
${ }^{1,2}$ Kashuba A.I., ${ }^{3,4}$ Zhydachevskyy Ya.A., ${ }^{4}$ Semkiv I.V., ${ }^{1}$ Franiv A.V. and \\ ${ }^{2}$ Kushnir O.S. \\ ${ }^{1}$ Physics Department, Ivan Franko National University of Lviv, 8a Kyrylo and \\ Mefodiy Street, 79005 Lviv, Ukraine \\ ${ }^{2}$ Electronics and Computer Technologies Department, Ivan Franko National \\ University of Lviv, 107 Tarnavsky Street, 79005 Lviv, Ukraine \\ ${ }^{3}$ Institute of Physics, Polish Academy of Sciences, Al. Lotników 32/46, \\ 02-668 Warsaw, Poland \\ ${ }^{4}$ General Physics Department, Lviv Polytechnic National University, \\ 12 Bandera Street, 79646 Lviv, Ukraine
}

Received: 31.10 .2017

\begin{abstract}
Photoluminescence (PL) emission spectra are studied for $\mathrm{In}_{\mathrm{x}} \mathrm{Tl}_{1-\mathrm{x}} \mathrm{I}$ solid solution with $\mathrm{x} \approx 0.5$. Two broad bands located approximately at 1.6 and $2.2 \mathrm{eV}$ are found and their physical mechanisms are discussed. The low-energy band has not been earlier detected in the pure InI compound but resembles that observed in TlI. Time decay of the PL in $\operatorname{In}_{0.5} \mathrm{Tl}_{0.5} \mathrm{I}$ is studied. Strong temperature dependence of the PL intensity is revealed. Optical absorption edge in $\operatorname{~n}_{0.5} \mathrm{Tl}_{0.5} \mathrm{I}$ is found to be formed predominantly by inter-cation transitions. PL excitation spectra are measured for the light wavelengths 570 and $800 \mathrm{~nm}$ and their parameters are evaluated.
\end{abstract}

Keywords: photoluminescence, luminescence decay, excitation spectra, excitons, InI-TII solid solutions.

PACS: $78.55 .-\mathrm{m}$

UDC: $535.37,538.958$

\section{Introduction}

Optical properties of layered thallium and indium halide crystals, including solid solutions $\mathrm{In}_{\mathrm{x}} \mathrm{Tl}_{1-\mathrm{x}} \mathrm{I}$, attract attention of many researchers [1-5]. In particular, this is because these materials can prove to be promising for ionizing-radiation detectors [5]. Moreover, although thallium iodide is crystallized in orthorhombic structure at the temperatures lower than $442 \mathrm{~K}$ and atmospheric pressure, it reveals an interesting transformation into a cubic, CsCl-like structure at higher temperatures. Some results concerned with this structural transition have been reported in Ref. [6]. Notice that no phase transition occurs in indium halides, except for InCl. Similarly to pure indium halides (see Ref. [7]), layered $\mathrm{In}_{\mathrm{x}} \mathrm{Tl}_{1-\mathrm{x}} \mathrm{I}$ crystals are easily cleaved perpendicular to the crystallographic $b$ axis. Substitution solid solutions of InI-TII system with different concentrations $\mathrm{x}$ are expected to combine the physical properties of InI and a low-temperature isostructural modification of TlI.

Recently the $\operatorname{In}_{\mathrm{x}} \mathrm{Tl}_{1-\mathrm{x}} \mathrm{I}$ system has been investigated with respect to its mechanical properties, phonon spectra and some optical features [5, 8-10]. In particular, the authors of the study [10] have predicted that InI can serve as a matrix for inclusion of TII quantum dots. As compared with pure InI, a decrease in the lattice parameters $b$ and $c$, accompanied with increase in the parameter $a$ and decrease in the lattice volume, have been observed in $\operatorname{In}_{0.5} \mathrm{Tl}_{0.5} \mathrm{I}$ [9], which can indicate a possible structural transformation in this compound.

Ukr. J. Phys. Opt. 2018, Volume 19, Issue 1 
Physical mechanisms forming radiative recombination transitions in indium(I) iodide crystals have been discussed in the experimental works [7, 11]. Moreover, photoluminescence (PL) spectra of InI and TII have been reported in Ref. [1, 7, 11]. In spite of some experimental information available for the pure indium and thallium iodides, the PL properties of their solid solutions have in fact not been investigated. As far as we know, there is also no data on the PL excitation spectra and the temperature behaviour of PL for the $\mathrm{In}_{\mathrm{x}} \mathrm{Tl}_{1-\mathrm{x}} \mathrm{I}$ solid solutions. The only exception is the study [12] performed on $\operatorname{In}_{\mathrm{x}} \mathrm{Tl}_{1-\mathrm{x}} \mathrm{I}(\mathrm{x}=0.4$ and 0.9$)$ incorporated into micro- or nanopores in a number of dielectric matrices. However, the measurements of the PL spectra in that work have been restricted to the region of fundamental absorption edge $(\sim 2.3 \div 2.5 \mathrm{eV})$ only. Moreover, our close analysis has demonstrated that the $\mathrm{In}_{\mathrm{x}} \mathrm{Tl}_{1-\mathrm{x}} \mathrm{I}$ compounds dealt with in the study [12] represent in fact thin films rather than bulk single crystals. Of course, the PL data for the $\mathrm{In}_{\mathrm{x}} \mathrm{Tl}_{1-\mathrm{x}} \mathrm{I}$ single crystals at low enough (e.g., liquid-helium) temperatures, where the emission is not quenched, would have been the most useful.

Below we report first-time investigations of the PL spectra for $\operatorname{In}_{\mathrm{x}} \mathrm{Tl}_{1-\mathrm{x}} \mathrm{I}(\mathrm{x} \approx 0.5)$ in the ultraviolet-visible wavelength range $(250-850 \mathrm{~nm})$. The temperature behaviour of the PL in a wide temperature range $(4.5-300 \mathrm{~K})$ and the PL excitation spectra are also studied. Finally, possible physical mechanisms for the PL bands are discussed.

\section{Experimental}

It is well known that the phase diagram of InI-TII system allows for solid solutions in the range $\mathrm{x}=0.3 \div 1.0$. In the present work we intended to synthesize and grow single crystals with equal contents of indium and thallium, i.e. with $\mathrm{x}=0.5$. We used binary single crystals InI and TlI taken according to equimolar ratio $(15.020 \mathrm{~g}$ of TlI and $10.930 \mathrm{~g}$ of $\mathrm{InI})$ as starting materials for the synthesis of $\operatorname{In}_{0.5} \mathrm{Tl}_{0.5} \mathrm{I}$. Our single crystals were grown with a standard Bridgman-Stockbarger technique in a furnace at $445^{\circ} \mathrm{C}$ and the temperature gradient $\Delta T / \Delta z \sim 1 \mathrm{~K} / \mathrm{mm}$, using quartz ampoules. The ampoules were pulled down into the furnace at the speed of $3 \mathrm{~mm} / \mathrm{h}$ for $48 \mathrm{~h}$. After that, we annealed the crystals in the same furnace. This was done at the temperature $T=180^{\circ} \mathrm{C}$ during $24 \mathrm{~h}$. Issuing from the study [9] and our further refined structural data, we have found that our samples are characterized by the concentration value $\mathrm{x}=0.50 \pm 0.05$.

PL and PL excitation spectra were measured using a Horiba/Jobin-Yvon Fluorolog-3 spectrofluorometer equipped with a continuous xenon lamp $(450 \mathrm{~W})$ and a Hamamatsu R928P photomultiplier. The PL excitation spectra were corrected for the emission spectrum of the lamp. The PL spectra were corrected for the spectral response of the spectrometer system used in our experiments. Finally, low-temperature PL measurements were performed using a continuous-flow liquid-helium cryostat.

We performed density-of-states calculations in the frame of generalized gradient approximation, using a Perdew-Burke-Ernzerhof exchange-correlation functional [13]. Interaction of electrons with atomic cores was described by Vanderbilt ultrasoft pseudopotentials [14].

\section{Results and discussion}

The PL emission bands detected for $\mathrm{In}_{0.5} \mathrm{Tl}_{0.5} \mathrm{I}$ at different temperatures are shown in Fig. 1 . A broad high-energy PL band is observed around $2.2 \mathrm{eV}$. Another broad band, which is much stronger, is located in the low-energy region (approximately at $1.6 \mathrm{eV}$ ). These bands referred further on to as the bands ' 1 ' and ' 2 ' are quenched notably with increasing temperature (see Fig. 1). As a result, it is difficult to distinguish unambiguously these bands already at the temperatures $T \geq 180 \mathrm{~K}$. 
It is evident from Fig. 2 that temperature quenching of the luminescence band 1 is accompanied with a shift of its maximum position towards lower photon energies, while the band 2 shifts towards higher energies under the same condition. It is worth mentioning that, in a fairly good approximation, the shifts of the maxima positions $E_{\max }$ of the PL bands 1 and 2 depend linearly on the temperature. The slopes of the $E_{\max }(T)$ dependences are equal to $6.6 \times 10^{-4}$ and $4.9 \times 10^{-4} \mathrm{eV} / \mathrm{K}$ respectively for the bands 1 and 2 . The main regularities found by us for the temperature dependences of maximal and integral PL intensities for the bands 1 and 2 will be reported and discussed elsewhere.

The band 2 observed at $1.6 \mathrm{eV}$ reveals a large Stokes shift and has a nearly symmetric Gaussian-type shape, with the width $\sim 0.12 \mathrm{eV}$. Although the nature of this band is not quite understood at present, it is probably formed by deep localized states. This point will be further elucidated below. Note also that a similar band centred at about $2.36 \mathrm{eV}$ (at $T \approx 2 \mathrm{~K}$ ) has earlier been observed for the pure binary TII compound [1]. Moreover, its width $(\sim 0.15 \mathrm{eV}-$ see Ref. [1]) is close to that found for $\operatorname{In}_{0.5} \mathrm{Tl}_{0.5}$ I. On the other hand, no traces of analogue of the band 2 have ever been detected in the indium iodide crystals, at least inside the photon-energy ranges dealt with in the works $[7,11,12]$ (typically at $E>1.9 \mathrm{eV}$ ). This implies that, although our solid solution is 'equidistant' from pure indium and thallium iodides, its PL properties can prove to be somewhat closer to those of the latter compound.

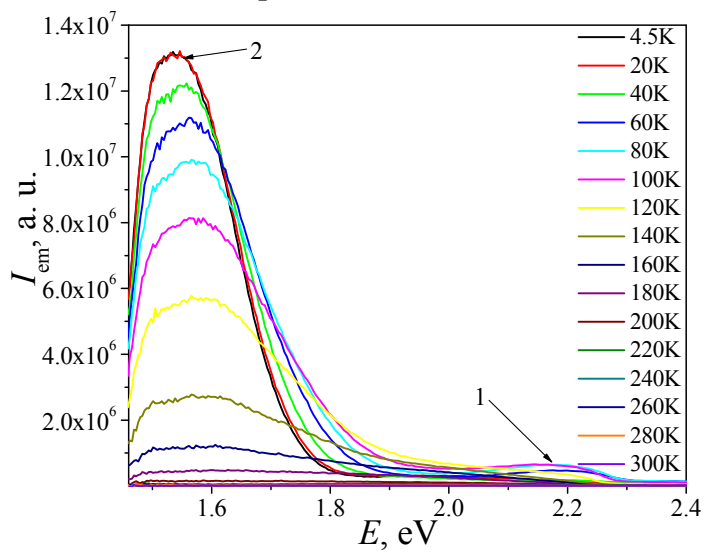

Fig. 1. PL emission spectra of $\operatorname{In}_{0.5} \mathrm{TI}_{0.5} \mid$ obtained at different temperatures indicated in the legend.

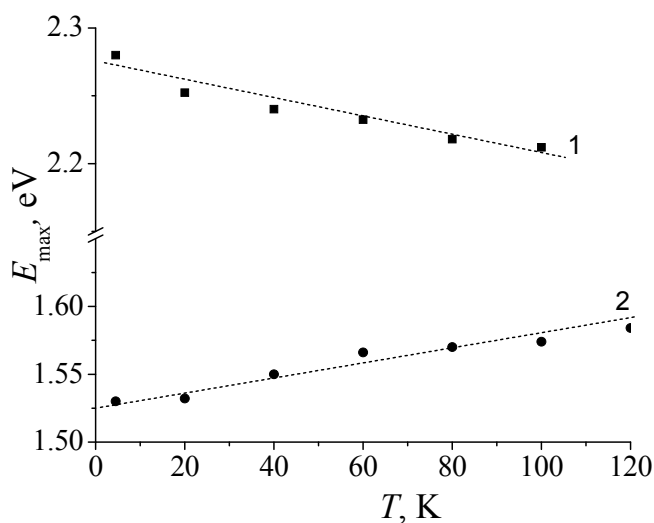

Fig. 2. Phonon-energy positions $E_{\max }$ of maxima of the $\mathrm{PL}$ bands 1 and 2 (see Fig. 1) measured for $\left|\mathrm{In}_{0.5} \mathrm{Tl}_{0.5}\right|$ as functions of temperature. Dashed lines correspond to linear fits. 
Now we proceed to the density-of-states calculation data in relation to the fundamental absorption edge and the PL properties of $\operatorname{In}_{0.5} \mathrm{Tl}_{0.5} \mathrm{I}$. When InI is 'mixed' with TII, In cations are substituted for $\mathrm{Tl}$ ones. As seen from Fig. 3, the highest valence band for the $\mathrm{In}_{0.5} \mathrm{Tl}_{0.5} \mathrm{I}$ compound consists of Tl $6 s$ (In $5 s$ ) and I $5 p$ orbitals. The lowest conduction bands are filled by In $6 p$ (Tl 7p) states. According to the results $[5,15]$, one can also state that the smallest bandgap intervals are located at $\mathrm{Z}-\Gamma$ edges. As a result, the optical-absorption edge appears predominantly due to intercation transitions. This situation is also typical for indium iodide [15]. Finally, the bandgap at low temperatures is formed by $\mathrm{Tl}^{+}\left(\mathrm{In}^{+}\right)$ions, which are the nearest neighbours of $\mathrm{I}^{-}$ions. In analogy to the results [3] and [12] on the TlBr and InI-TII systems, one can assume that the localized excitons related to the $\mathrm{I}^{-}$ions are formed via recombination of trapped holes and electrons.

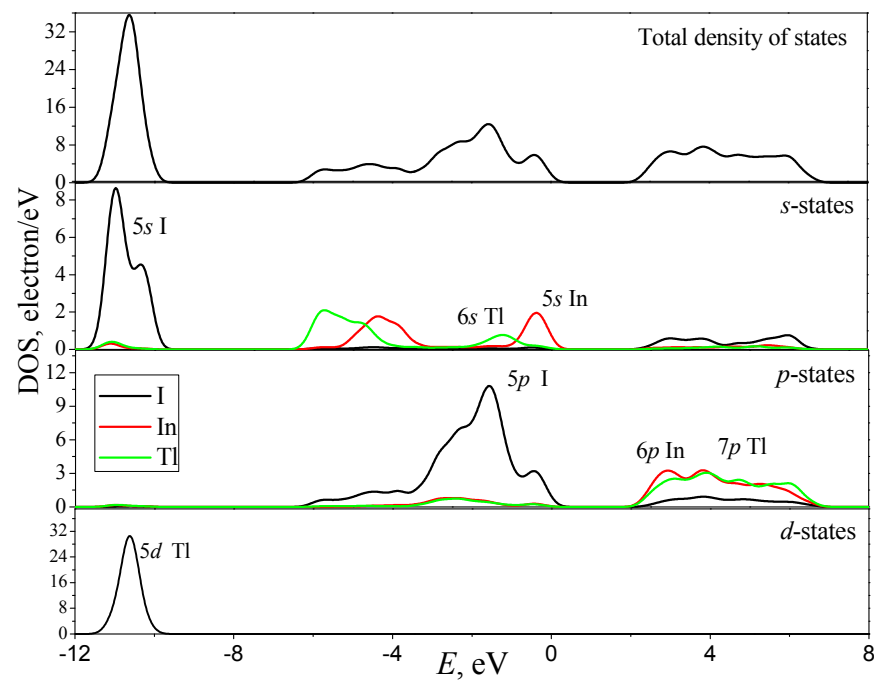

Fig. 3. Density of states calculated for the $\ln _{0.5} \mathrm{TI}_{0.5} \mathrm{I}$ crystals.

Fig. 4 displays time decay of the PL bands 1 and 2 observed in the $\operatorname{In}_{0.5} \mathrm{Tl}_{0.5} \mathrm{I}$ crystals. Notice that 'heads' (i.e., short- $t$ regions) of the $I_{\mathrm{em}}(t)$ curves are dominated by a well-known effect of optical chopper, which masks a true decay process. It is especially peculiar for the temporal profile found for the band 2. As a result, our main subject are 'tails' (i.e., longest- $t$ regions) of the $I_{\mathrm{em}}(t)$ dependences. As evident from the semi-logarithmic plots in Fig. 4, a standard single-exponential function

$$
I_{\mathrm{em}}(t) \propto \exp (-t / \tau)
$$

(with $\tau$ being the characteristic decay time) does not represent the best model for describing the time relaxation of the PL intensity in $\mathrm{In}_{0.5} \mathrm{Tl}_{0.5}$. The goodness of the corresponding nonlinear fit is obviously insufficient, with the coefficient of determination being of the order of $R^{2} \approx 0.94 \div 0.95$ only.

The $\mathrm{R}^{2}$ parameter becomes somewhat larger $\left(\mathrm{R}^{2} \approx 0.97 \div 0.99\right)$ if we try some other counterparts of the single-exponential function known from the literature, namely a generalized hyperbolic function

$$
I_{\mathrm{em}}(t) \propto(t / \tau)^{-\alpha}(\tau, \alpha=\text { const })
$$

and a stretched exponential

$$
I_{\mathrm{em}}(t) \propto \exp \left[-(t / \tau)^{\beta}\right] \quad(\tau, \beta=\text { const, } 0<\beta \leq 1) .
$$


The technical problems of fitting with Eqs. (2) and (3) can be reduced to a standard linearregression task, when plotting the dependences $I_{\mathrm{em}}(t)$ and $\lg I_{\mathrm{em}}(t)$ on a double logarithmic scale. The linear fit yields in the parameters $\alpha \sim 0.5$ and $\beta \sim 0.1 \div 0.2$ for the both PL bands 1 and 2 . Since the appropriate goodness-of-fit is high enough, the both models cannot be easily rejected by the experimental data. It is known that the model given by Eq. (2) implies the influence of some recombination processes and the corresponding traps. According to Eq. (3), the characteristic decay time $\tau$ is continuously distributed due to structural heterogeneities or for some other related reasons, e.g. multipole-interaction mechanisms (see Ref. [16]).

Finally, the $I_{\mathrm{em}}(t)$ dependences for the both PL bands 1 and 2 are the best fitted with the twoexponential function

$$
I_{\mathrm{em}}(t)=A_{1} \exp \left(-t / \tau_{1}\right)+A_{2} \exp \left(-t / \tau_{2}\right)
$$

where $A_{1,2}$ denote constant amplitude factors and $\tau_{1,2}$ characteristic decay times. We obtain extremely high $\mathrm{R}^{2}$ values $(0.999 \div 0.9999)$ for the fitting with Eq. (4) (see Fig. 4). The two decay components for the emission band 1 are described by the characteristic times $\tau_{1}=182 \pm 4 \mathrm{~ns}$ and $\tau_{2}=1.24 \pm 0.02 \mu \mathrm{s}$, whereas the emission band 2 located at $1.6 \mathrm{eV}$ is characterized by the parameters $\tau_{1}=1.05 \pm 0.01 \mu \mathrm{s}$ and $\tau_{2}=16.93 \pm 0.41 \mu \mathrm{s}$. The ratios of the corresponding 'decay amplitudes' $A_{i}$ involved in Eq. (4) are equal to $A_{2} / A_{1} \approx 0.36$ and $A_{2} / A_{1} \approx 3 \times 10^{-6}$ for the PL bands 1 and 2 , respectively. In other words, the 'ultraslow' luminescence decay channel for the band 2 is very weak, though being important in accurate quantitative description of the luminescence decay. Notice also that, since the PL emission in the band 1 decays notably with increasing temperature (see Fig. 1), one can suppose that self-trapped holes are thermally activated and can migrate through the crystal to form a localized bounded exciton emitting at $\sim 2.2 \mathrm{eV}$ (see Refs. [3, 12]).
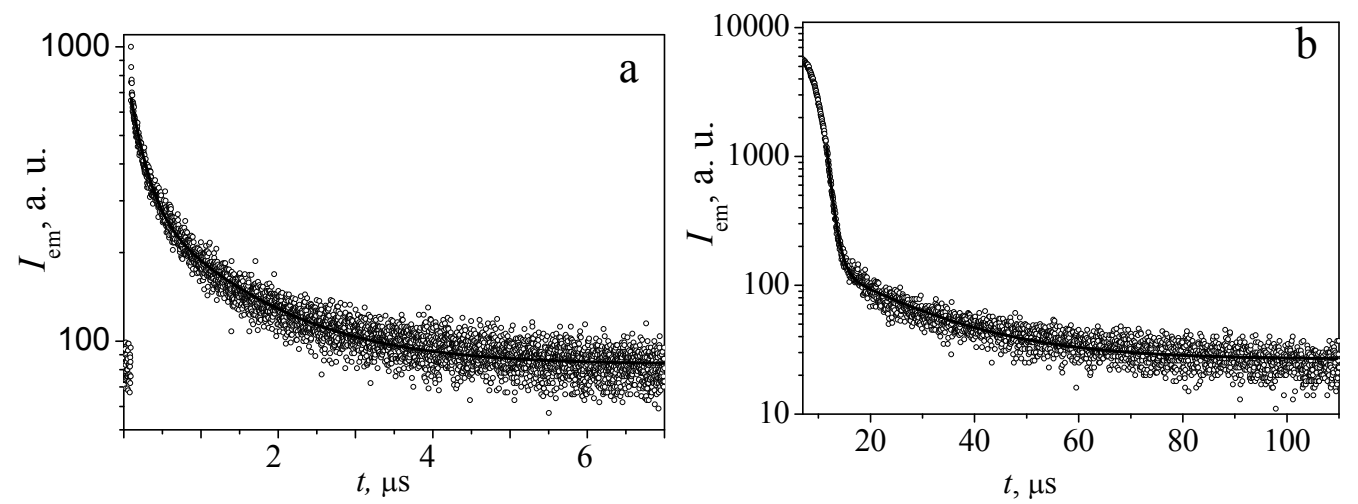

Fig. 4. $P L$ decay curves of $\ln _{0.5} \mathrm{TI}_{0.5} \mathrm{I}$ measured for (a) band $1\left(\lambda_{\mathrm{ex}}=371 \mathrm{~nm} ; \quad T=100 \mathrm{~K}\right)$ and (b) band 2 $\left(\lambda_{\mathrm{ex}}=450 \mathrm{~nm} ; T=4.5 \mathrm{~K}\right)$. Solid lines correspond to fitting with Eq. (4) (see the text).

Basing on our density-of-state and PL kinetics data, as well as the results known from the literature, one can discuss the PL bands 1 and 2 in more detail. The PL emission band 1 has been thoroughly interpreted in InI [7, 12], TII [1, 4] and $\mathrm{TlBr}$ [3], including the cases of cation admixtures and the corresponding decay curves [3, 4]. It can be attributed to disappearance of a self-trapped state of indirect exciton formed by $\mathrm{I}^{-}$ions. According to the results [3] (see also [12]), one can assume that the fast-decay component of the PL band 1 located near $2.2 \mathrm{eV}$ is formed due to a mixed singlet-triplet state of the exciton. Its slowly decaying component can be attributed to a triplet state of the exciton, which is weakly allowed by the contribution of $p$ and/or $d$ states of the halogen ion.

Ukr. J. Phys. Opt. 2018, Volume 19, Issue 1 
It would be natural to associate the PL band 2 centred approximately at $1.6 \mathrm{eV}$ with the recombination of electron-hole pairs, with participation of donor and acceptor levels. In our opinion, here deep traps related somehow to structural imperfections can be involved (see also the discussion in Ref. [17]). A similar mechanism has earlier been suggested for the emission band 2 appearing in TII [1] (see also Ref. [3]). Moreover, it does not contradict a hint to complex recombination processes obtained from the PL decay curves given by Eqs. (2) and (3). Finally, the nature of the 'ultraslow' decay component for the PL band 2 should be a subject of further research.

Our last experiments have been concerned with the PL excitation spectra of $\operatorname{In}_{0.5} \mathrm{Tl}_{0.5} \mathrm{I}$. Fig. 5 shows the spectra obtained at 4.5 and $100 \mathrm{~K}$. With high enough accuracy, the both spectra can be described well as superposition of Gaussian components. The parameters obtained using a standard Gaussian fit are presented in Table 1. To perform closer interpretation of the excitation spectra, one needs accurate experimental energy-band structure data. EPR time-resolved luminescence and thermally stimulated luminescence data for the crystals under test would also be of aid in this respect (see, e.g., [18]).
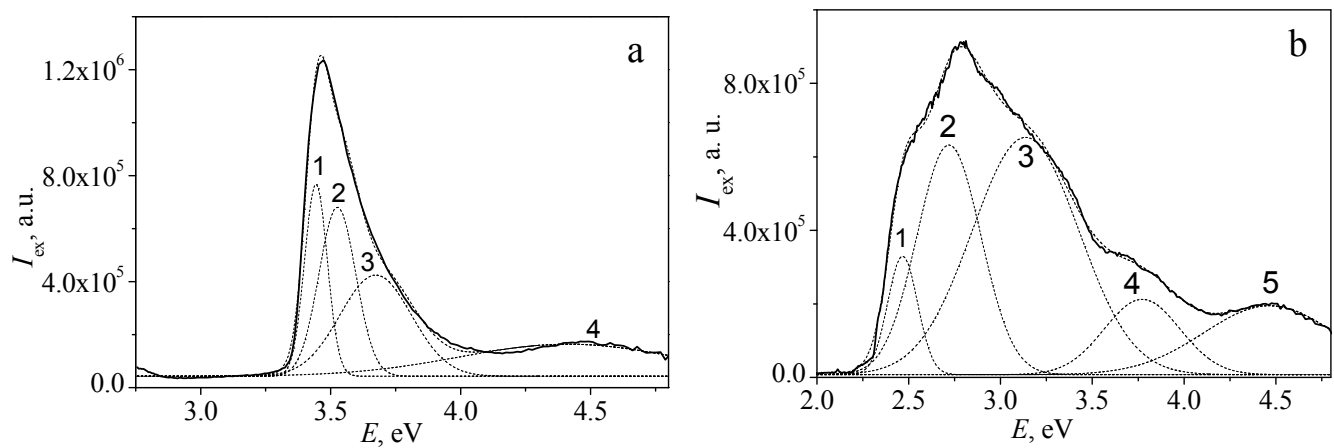

Fig. 5. $\mathrm{PL}$ excitation spectra for $\mathrm{In}_{0.5} \mathrm{TI}_{0.5} \mathrm{I}$ as measured at (a) $100 \mathrm{~K}\left(\lambda_{\mathrm{em}}=570 \mathrm{~nm}\right)$ and (b) $4.5 \mathrm{~K}\left(\lambda_{\mathrm{em}}=800 \mathrm{~nm}\right)$. Dashed lines are Gaussian components.

Table 1. Parameters of Gaussian peaks calculated for the PL excitation spectra of $\operatorname{In}_{0.5} \mathrm{Tl}_{0.5} \mathrm{I}$ for the cases of $\lambda_{\mathrm{em}}=570$ and $800 \mathrm{~nm}$ : FWHM denotes full width of a peak at its half maximum.

\begin{tabular}{cccc}
\hline$\lambda_{\mathrm{em}}=570 \mathrm{~nm}$ & Peak position, eV & Peak FWHM, meV & Maximal peak intensity $I_{\max }, 10^{5}$ a. u. \\
\hline Peak 1 & 4.42 & 47.9 & 6.911 \\
Peak 2 & 3.66 & 26.7 & 6.301 \\
Peak 3 & 3.52 & 14.3 & 4.036 \\
Peak 4 & 3.44 & 9.1 & 1.197 \\
\hline$\lambda_{\text {em }}=800 \mathrm{~nm}$ & Peak position, eV & Peak FWHM, meV & Maximal peak intensity $I_{\max }, 10^{5}$ a. u. \\
\hline Peak 1 & 4.46 & 41.8 & 3.607 \\
Peak 2 & 3.81 & 28.9 & 7.850 \\
Peak 3 & 3.21 & 67.7 & 5.457 \\
Peak 4 & 2.74 & 62.8 & 1.523 \\
Peak 5 & 2.46 & 34.9 & 1.797 \\
\hline
\end{tabular}

\section{Conclusions}

Summing up, in this work we have studied experimentally the PL properties of the $\operatorname{In}_{\mathrm{x}} \mathrm{Tl}_{1-\mathrm{x}} \mathrm{I}$ single crystals, using the compound $\mathrm{x} \approx 0.5$ as example. The two bands termed conventionally as ' 1 ' and ' 2 ' are observed in the PL emission spectra close by 2.2 and $1.6 \mathrm{eV}$, respectively. A strong effect 
of temperature on the both PL emission bands has been revealed in the range from 4.5 to $300 \mathrm{~K}$. It has been revealed that temperature quenching of the PL in $\mathrm{In}_{0.5} \mathrm{Tl}_{0.5} \mathrm{I}$ is accompanied with a shift of the band 1 towards lower photon energies, while the sign of the shift typical for the PL band 2 is opposite. Issuing from our density-of-state calculations, we have concluded that the optical absorption edge is formed mainly by the inter-cation transitions.

The decay curve for the PL band 1 is the best described as a superposition of two exponential components having the characteristic times close to $182 \mathrm{~ns}$ and $1.24 \mu \mathrm{s}$. The same components for the PL band 2 are determined by the decay times $1.05 \mu \mathrm{s}$ and $16.93 \mu \mathrm{s}$. The excitation spectra of $\mathrm{In}_{0.5} \mathrm{Tl}_{0.5} \mathrm{I}$ have also been measured. We have successfully decomposed these spectra into several Gaussian constituents.

Finally, basing on our experimental results and DOS calculations, we suppose that the PL emission band 1 centred around $2.2 \mathrm{eV}$ is caused by annihilation of bound excitons, whereas the band 2 located at about $1.6 \mathrm{eV}$ is due to recombination of electron-hole pairs, with participation of donor and acceptor levels. The availability in $\mathrm{In}_{0.5} \mathrm{Tl}_{0.5} \mathrm{I}$ of the low-energy PL band similar to that observed in TII indicates that the PL and, perhaps, some other physical properties of our borderline solid solution can turn out to be somewhat closer to the properties characteristic for pure thallium iodide rather than indium iodide.

\section{References}

1. Ohno N, Nakamura K and Nakai Y, 1987. Multiple LO phonon scattering in orthorhombic thallous iodide. J. Phys. Soc. Japan. 56: 2565-2569.

2. Kolinko M I, Bovgyra O V and Piasecki M, 2001. Optical constants of indium bromide. Low Temp. Phys. 27: 153-157.

3. Fujii A, Takiyama K, Haraguchi T, Miyazaki K and Tabuki M, 2004. Time-resolved photoluminescence due to STE in TlBr doped with $\mathrm{I}^{-}$ions. J. Lumin. 108: 81-84.

4. Ohno N, 2006. Time-resolved photoluminescence of exciton-polaritons in orthorhombic TlI. J. Lumin. 119-120: 47-50.

5. Xu Z P, Wang Y Z, Zhang W, Wang Q and Wu G Q, 2014. First-principle study on the effects of $\mathrm{Tl}$ doping on the band gap and the band-edge of optical absorption of InI. Acta Phys. Sin. 63: 147102 .

6. Lowndes R P and Perry C H, 1973. Molecular structure and anharmonicity in thallium iodide. J. Chem. Phys. 58: 271-278.

7. Yoshida M, Ohno N, Watanabe H, Nakamura K and Nakai Y, 1984. Exciton transitions in indium halides. J. Phys. Soc. Japan. 53: 408-418.

8. Kashuba A I, Franiv A V, Bovgyra O V and Brezvin R S, 2017. Birefringence of $\operatorname{In}_{\mathrm{x}} \mathrm{Tl}_{1-\mathrm{x}} \mathrm{I}$ solid state solution. Funct. Mater. 23: 26-30.

9. Kashuba A I and Apunevych S V, 2016. Phonon spectrum of crystals $\operatorname{In}_{\mathrm{x}} \mathrm{Tl}_{1-\mathrm{x}} \mathrm{I}$ substitutional solid solutions. J. Nano-Electron. Phys. 8: 1010-1-1010-5.

10. Franiv A V, Stadnyk V Y, Kashuba A I, Brezvin R S, Bovgira O V and Futei A V, 2017. Temperature behavior of thermal expansion and birefringence of $\operatorname{In}_{\mathrm{x}} \mathrm{Tl}_{1-\mathrm{x}} \mathrm{I}$ substitution solid solutions. Opt. Spectrosc. 123: 177-180.

11. Ohno N, Yoshida M, Nakamura K and Nakai Y, 1980. Photoluminescence of indium iodide. Solid State Commun. 35: 775-779.

12. Franiv A, Peleshchyshyn R and Kolosivski Y, 2000. Optical properties of quantum size nanocrystals $\mathrm{In}_{\mathrm{x}} \mathrm{Tl}_{1-\mathrm{x}} \mathrm{I}$ embedded in solid matrices. Ukr. J. Phys. Opt. 1: 24-27. 
13. Perdew J P, Burke K and Ernzerhof M, 1996. Generalized gradient approximation made simple. Phys. Rev. Lett. 77: 3865-3868.

14. Vanderbilt D, 1990. Soft self-consistent pseudopotentials in a generalized eigenvalue formalism. Phys. Rev. B. 41: 7892-7895.

15. Kolinko M I, 1997. Density of states of InI: theoretical and experimental investigation. Phys. Rev. B. 55: 4007-4010.

16. Benny Lee K C, Siegel J, Webb S E D, Lévêque-Fort S, Cole M J, Jones R, Dowling K, Lever M J and French P M W, 2001. Application of the stretched exponential function to fluorescence lifetime imaging. Biophys. J. 81: 1265-1274.

17. Wojtowicz A J, Glodo J, Drozdowski W and Przegietka K R, 1998. Electron traps and scintillation mechanism in $\mathrm{YAlO}_{3}: \mathrm{Ce}$ and $\mathrm{LuAlO}_{3}$ :Ce scintillators. J. Lumin. 79: 275-291.

18. Kindrat I I, Padlyak B V and Drzewiecki A, 2017. Intrinsic luminescence of un-doped borate glasses. J. Lumin. 187: 546-554.

Kashuba A.I., Zhydachevskyy Ya.A., Semkiv I.V., Franiv A.V. and Kushnir O.S. 2018. Photoluminescence in the solid solution $\mathrm{In}_{0.5} \mathrm{Tl}_{0.5} \mathrm{I}$. Ukr.J.Phys.Opt. 19: $1-8$.

Анотація. Експериментально досліджено спектри випромінювання фотолюмінесценції (ФЛ) для твердого розчину $\operatorname{In}_{x} T l_{1-x} I$ при $x \approx 0,5$. Виявлено дві широкі смуги ФЛ, розташовані приблизно при 1,6 i 2,2 еВ, і обговорено їхні фізичні механізми. Низькоенергетична смуга, яку не було виявлено в чистому InI, нагадує смугу, спостережену раніше в TlI. Вивчено часове затухання ФЛ в $\mathrm{In}_{0.5} \mathrm{Tl}_{0.5} \mathrm{I}$. Виявлено значну температурну залежність інтенсивності ФЛ. Показано, що край оптичного поглинання $\operatorname{In}_{0,5} T_{0,5} I$ формується переважно міжкатіонними переходами. Виміряно спектри збудження ФЛ для довжин хвиль $570 i$ 800 нм і оичнено їхні параметри. 